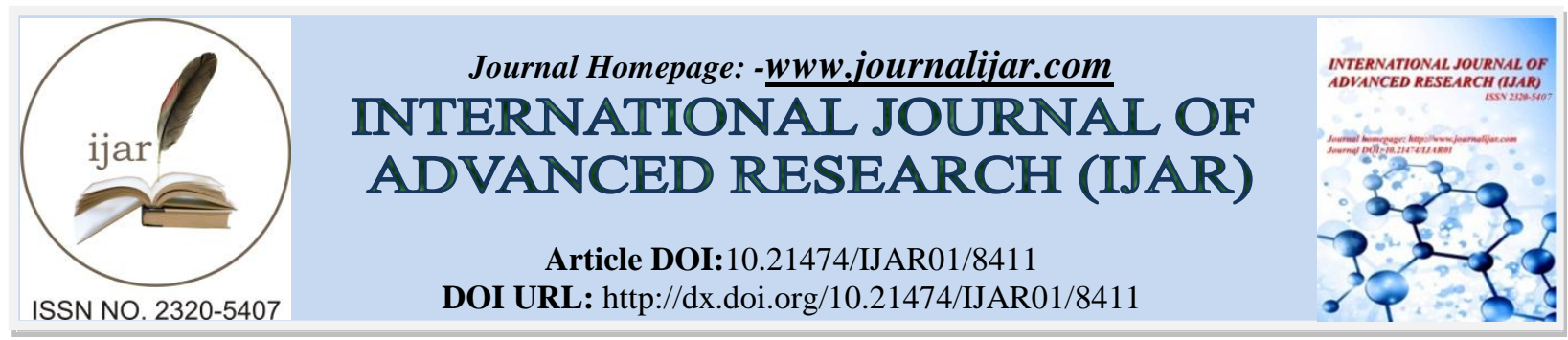

RESEARCH ARTICLE

\title{
CURRENT STATUS OF HIV VACCINATION STRATEGY AND ITS IMPLICATION ON A DEVELOPING COUNTRY LIKE INDIA- A MINI-REVIEW.
}

\author{
Aroni Chatterjee ${ }^{1}$, Hiya Ghosh ${ }^{2}$, S Pain ${ }^{3}$ and Agnibha Maiti ${ }^{3}$. \\ 1. Virus Research Laboratory, National Institute of Cholera and Enteric Diseases, Kolkata, India. \\ 2. Department of Endocrinology and Metabolism, IPGMER \& SSKM Hospital, Kolkata, India. \\ 3. Department of Medicine, IPGMER \& SSKM Hospital, Kolkata, India.
}

\section{Manuscript Info}

\section{Manuscript History}

Received: 14 November 2018

Final Accepted: 16 December 2018

Published: January 2019

Key words:-

Human immunodeficiency virus,

Epidemic, Vaccination,

Immunocompromized, AIDS, ART.

\begin{abstract}
At a time when numerous infectious diseases are kept under control with worldwide vaccination endeavors, the human immunodeficiency infection (HIV), identified in 1984, is still infecting millions around the world. From 1990 to 2017 the number of individuals living with HIV ascended from below 8 million to more than 36.9 million. Since the start of the HIV scourge, the infection has claimed more than 34 million lives. While antiretroviral medicines have definitely enhanced life expectancy and quality of life for individuals living with HIV, preventing the occurrence of HIV infection is as yet the essential objective, particularly for the low-income nations that are hardest hit and can't bear the cost of prolonged medications. Many years of effort have been spent, towards developing a low cost, powerful and safe HIV vaccine yet till now nothing substantial has come up. India with its immense populace of HIV positive patients is also taking a functioning part in this procedure. This review hereby provides a concise story of the currently adopted strategies involved in developing an effective HIV vaccine and also about the role played by India in this global effort.
\end{abstract}

Copy Right, IJAR, 2018,. All rights reserved.

\section{Introduction:-}

Human Immunodeficiency Virus (HIV) infection is currently a major public health concern throughout the globe. People who are infected with the virus have to bear its burden throughout their lifetime and have to live with a compromised immune system which renders them prone to different opportunistic infections. The virus specifically targets and kills immune T helper cells called CD4+ lymphocyte cells, which are the coordinators of cell mediated immunity in humans. When the number of CD4+ cells drops below a certain point, a person is considered to have progressed from HIV infection to AIDS. Till 2018, about 37 million people worldwide were living with HIV. A recent UN report found that new infections have increased in several parts of the world $(1,2)$. In Eastern Europe and Asia, there was a 57\% increase in annual new infections reported from 2010 to 2017. Similarly, rates have soared in many parts of Africa, the continent that has the biggest AIDS epidemic (2). Persistent efforts by scientists around the world for effective HIV treatments and easier accessibility to effective treatments has somewhat reduced the soaring spread of the disease among the masses. Thanks to their combined effort with ARV therapy, more than 13 million HIV-related deaths were averted in the last two decades (3). An effective vaccine against HIV is the need of the

Corresponding Author:-Agnibha Maiti.

Address:-Department of Medicine, IPGMER \& SSKM Hospital, Kolkata, India. 
hour. To date, over 40 different HIV vaccines have been tested in several thousand volunteers. Most of this research has consisted of early safety and efficacy studies of recombinant proteins, produced in a variety of different systems. Despite some encouraging evidence of immune responses in people, it is unclear whether these vaccines would be completely effective against HIV infection. This review highlights the different aspects and strategies involved with HIV vaccination and also discuss the current status of HIV vaccination programmes in India.

\section{Different forms of HIV vaccines}

Researchers have explored a number of strategies that they hope will produce protective immune responses.

\section{Live attenuated vaccines}

One of the most effective ways to create vaccines is by 'attenuating' the pathogen. These weakened viruses are avirulent, but has the ability to generate an immune response in the body. Creating live attenuated vaccines normally involves deleting genes that protect the virus against the immune system, but which are not essential for its reproduction. The measles vaccine is an example. Live attenuated HIV vaccines are currently considered unsafe, after research in monkeys indicated that a live-attenuated vaccine, made by deleting the nef gene, protected monkeys against SIV, but caused AIDS, albeit more slowly than the normal virus (5).

\section{Inactivated vaccines}

Creating vaccines based on killed or inactivated viruses is another classic technique, which was used in creating the first successful polio vaccine. However, the technique is considered risky, as vaccine recipients could easily be infected with HIV if the inactivation process should fail. There have been no claims of a significant level of success with these types of vaccine for HIV, although some, such as Remune, an HIV preparation with envelope protein gp120 removed, were investigated as possible therapeutic vaccines for people already infected with HIV (6).

\section{Peptide vaccines}

Peptide vaccines have been tested in HIV-positive patients, with some antibody and cellular immune responses against HIV. A vaccine containing the V3 sequences from several strains of HIV has been used in animals and produced antibodies that neutralize several laboratory-adapted virus strains (7). Linking a peptide to a lipid has also been explored as an HIV vaccine technique. The lipid carries the peptide directly into cell membranes where it can be presented to the immune system with maximum efficiency.

\section{Modified envelope vaccines}

Other strategies for stimulating the immune system to produce antibodies have stemmed from better understanding of the way HIV's proteins interact with the cells they infect. For example, HIV's proteins are often hidden from the immune system by a coating of sugar molecules: removing some of these molecules from the protein's surface may lead to neutralising antibodies that can act against the virus (8).

\section{DNA vaccines}

DNA vaccines are small pieces of DNA containing genes from HIV, which can be grown in bacteria. After injection, the host's cells effectively make the vaccine themselves by expressing the HIV genes. Although they work well in mice, it has been more difficult to get DNA vaccines to work in primates, including humans, as it is difficult to get enough DNA into each injection (9).

\section{Recombinant sub-unit vaccines}

Recombinant sub-unit vaccines stimulate antibodies to HIV by mimicking proteins on the surface of HIV. A range of HIV proteins has been produced as potential vaccines for HIV. Initially, the main targets for vaccine developers were the viral envelope protein gp120, and its precursor gp160, in the hope that they would prevent HIV entering human cells. These were the basis for the AIDSVAX vaccines $(10,11)$.

\section{Recombinant vectored vaccines}

Recombinant vectored vaccines are most often used for vaccines that attempt to stimulate cellular immunity, as the vaccine acts more literally like an infection than vaccines which simply contain proteins or DNA. They are made by incorporating fragments of HIV into the shells of viruses that can infect cells but cause no or few symptoms, such as the canarypox viruses or adenoviruses (12). These vaccines infect cells and deliver their package of HIV components into the cell, causing it to display immunogenic epitopes. Most vector vaccines set up an ongoing but 
harmless infection within the body and therefore set up a lasting immune response to HIV. Vector vaccines have been shown to produce stronger HIV-specific cytotoxic T-cell (CD8) responses in animals and humans (13).

\section{Other vectors based vaccines}

Other viral vectors currently being studied with HIV or SIV in animals include rabies, measles, poliovirus, herpes simplex, human rhinovirus, influenza and pertussis (14).

Measles is of particular interest because the live attenuated measles vaccine in common use is extremely effective in generating long-lasting immune responses when given to infants. The recombinant rabies virus vaccine potentially has a number of advantages. Since few people are vaccinated against rabies, the attenuated rabies virus infects most human cells but does not cause any damage and it may produce ongoing exposure to HIV antigens in the body (15). One recent vaccine that has caused considerable excitement from its results in animal experiments used cytomegalovirus (CMV) as its vector (16).

\section{Replicon vaccines}

Replicons have the same physical properties as viruses and viral vectors, including the ability to enter cells of specific kinds, but they have the advantage of not reproducing after entering the human cell, so there is little or no immune response to the carrier virus. Thus, one replicon system could be used repeatedly in the same person, to deliver a series of different vaccines or gene therapies (17). The three leading replicon systems for HIV vaccines are based on Venezuelan equine encephalitis (VEE), Semliki forest virus (SFV), and adeno-associated virus (AAV). All three have shown some success in animal studies (18).

\section{Vaccines against viral toxins}

HIV produces several harmful proteins that could be vaccine targets. The most promising so far is the tat (transactivator) protein, which is produced early on in the viral lifecycle, before HIV integrates into the host genome. It stimulates the host cell's genes to become active and, released outside the cell, influences immune cells to develop in directions that make them more receptive to HIV. The tat protein is so important to HIV that it is highly conserved, and studies have shown that HIV in people with high levels of anti-tat antibodies progresses more slowly to AIDS, so a tat vaccine might also act as a therapeutic vaccine (19).

\section{Therapeutic vs. Preventive HIV vaccines}

A therapeutic HIV vaccine is a vaccine that is designed to improve the body's immune response to HIV in a person who already has a HIV infection. Researchers are developing and testing therapeutic HIV vaccines to slow down the progression of HIV infection and ideally result in undetectable levels of HIV without the need for regular antiretroviral therapy (ART). A therapeutic HIV vaccine may also slow a person's progression to AIDS and may make it less likely that a person could transmit HIV to others (20). A preventive HIV vaccine on the other hand is given to people who do not have HIV, with the goal of preventing HIV infection in the future. The vaccine would teach the person's immune system to recognize and effectively fight HIV in case the virus ever enters the person's body (21).

\section{HIV vaccination status-global scenario}

The first priority in light of the positive results from the largest HIV vaccine trial till date, the RV144 trial is for researchers to determine precisely how the prime-boost combination protected against infection with HIV (22). A recent study indicates that $\mathrm{T}$-cell responses likely did not play a role in protecting against infection, and that the vaccine's efficacy was related to antibody responses to certain regions of viral envelope proteins. Additional studies are ongoing to understand and improve upon the immune response generated in the RV144 trial (23). Researchers are also studying the methodology and administrative approaches of RV144, in hopes of applying the knowledge gleaned from the largest HIV vaccine trial in history to improve the design of future trials (24). Researchers are intricately studying those subjects who never become infected with HIV despite being exposed to it repeatedly and those whose HIV infections never progress to AIDS, in hopes that whatever innate ability they have to control HIV might provide new insights for future vaccine development. Many other vaccine candidates are in various stages of testing and development. In addition to the canarypox-based recombinant vaccine other recombinant candidates have also been developed based on adenovirus (25). The positive results of a SIV vaccine trial in rhesus macaque monkeys have raised the idea of using cytomegalovirus (CMV) as a vector in future HIV vaccine candidates. In this approach, $\mathrm{T}$ cells known as killer $\mathrm{T}$ cells, which can kill infected cells, provide the protection afforded by the vaccine. Other vaccine approaches are advancing, such as candidates that stimulate immune responses in the 
mucosal surfaces of the gut - the same site of early HIV replication (26). Finally, researchers are exploring ways of generating antibodies to HIV which will be able to neutralize the virus before they infect a person. These antibodies provide an excellent target for vaccine discovery by highlighting weaknesses on the surface of HIV.

\section{HIV vaccination status- Indian Scenario}

In the last few years, there have been active discussions in the media, newspapers and in journals, about issues related to how AIDS vaccine trials are being conducted in India. The International AIDS Vaccine Initiative (IAVI) has partnered with the ministry of health and family welfare in India through the National AIDS Control Organization (NACO) and the Indian Council of Medical Research (ICMR) since 2002 to implement the AIDS vaccine research and development programme (27). With all these organizations coming together, efforts have been put rightly to find and deliver an AIDS vaccine that the world so desperately needs. The Indian programme has prioritized vaccines designed to prevent clade $\mathrm{C}$ infections since this was the predominant subtype of HIV circulating in India (28). High-level science review meetings of national and international experts were held by ICMR from 2003 to 2005 to evaluate and review possible AIDS vaccines suitable for India (29). Representatives from various top notch Indian research institutions as well as medical experts were present. Several candidates were prioritized for testing, including a recombinant Adeno-associated Virus (AAV) vaccine and a recombinant Modified Vaccine Ankara (MVA) vaccine candidate. In the next year, the panel recommended that India should participate in the multi-country Phase I AAV-based AIDS vaccine clinical trial (29). The AAV study marked India's first ever AIDS vaccine trial and was part of a joint international protocol designed to generate reliable data on this vaccine candidate in different populations. This vaccine was designed by Targeted Genetics Corporation, a Seattle-based, public-listed biotechnology company, and Columbus Children's Research Institute (30). The trials conducted in India proved that AAV was safe and well tolerated by the Indian population. The Indian authorities and IAVI believed that it was important to have safety and immunogenicity data from India, as the vaccine candidate was specifically designed for the type of HIV circulating in Asia and Africa (31). Clearly, HIV is outpacing our response in India with a steady increase in the number of new HIV infections annually. While the government of India has implemented a number of prevention and treatment strategies, which have shown very positive results, the facts suggest that a great deal still remains to be done. A recent study has suggested that the HIV epidemic could largely impede India's developmental goals and can reduce the country's growth by as much as one percent in terms of GDP. The HIV epidemic thus requires a bold research initiative and focused development strategy from the government of India as an immediate measure.

\section{Discussion:-}

The development of a safe and effective HIV-1 vaccine remains one of the highest research priorities to create a world without AIDS. Although an effective prophylactic vaccine still remains elusive, the results of the RV144 trial have reenergized the HIV-1 vaccine landscape (32). The lessons learnt from this trial are currently being applied by scientists not only to develop modified and possibly more effective vaccine candidates but also to guide future vaccine trial protocols. The ability to express the native Envtrimer of HIV-1 as a recombinant protein has also been a major step forward in vaccine design and development (33). Furthermore, the results of some of the novel vaccine candidates in the non-human primate models have been quite encouraging. Evaluations of these novel immunogens in human trials, an increased understanding of immune pathways which lead to the generation of effective antibodies and the availability of modern tools to study the intricacies of the B cell response have the potential to further transform the field of HIV vaccine development (33). However, there are many areas of concern that will have to be addressed on a priority basis. One major concern is whether the immune correlates of vaccine protection derived from the RV144 trial can be applied to other modalities of vaccines and diverse subtypes. Adjuvant formulations which can enhance the humoral immune response and facilitate antigen dose sparing may also play a significant role in the design of a successful vaccine (34). Evaluation of diverse vaccine concepts and vaccination regimens in an accelerated and dynamic human vaccine trials program will clearly result in greater success in developing the vaccine (35). Greater investment in the development of infrastructure in countries which are experiencing the major brunt of the HIV/AIDS epidemic will also be essential to bring us closer to an effective vaccine. The bottom line is that there is an urgent need to explore strategies to design a truly global prophylactic vaccine which can address the extensive viral diversity and provide protection against all circulating strains. Discovery of a preventive vaccine to end the AIDS epidemic in the near foreseeable future can be possible by a truly unified global level comprehensive response involving all the stakeholders including researchers, clinicians, epidemiologists, national and international HIV/AIDS organisations, governments, local communities and the drug development industry. 


\section{Conclusion:-}

India currently hosts some four million HIV positive people, the second largest concentration in any country after South Africa. Though with the advent of ART and HAART, HIV related deaths has been largely averted but the incidence of persistent infections are precariously high. At this hour of grave danger an ideal HIV vaccine is the only ray of hope. A greater focus on basic and preclinical research in immunology is to be made so that it can provide the knowledge needed to guide the design of an effective HIV-1 vaccine. Basic research may indeed give us an understanding of how an immune response performs in case of certain HIV-1 infected persons but whether this knowledge will bring us closer to the goal of developing an effective vaccine remains an open question. It may therefore be wise to continue with exploratory early phase human trials and testing a variety of immunization strategies at the same time rather than waiting until we fully understand all the intricacies of the various types of immune responses to HIV-1 infection.

\section{References:-}

1. Murray CJ, Ortblad KF, Guinovart C, Lim SS, Wolock TM, Roberts DA, et al. Global, regional, and national incidence and mortality for HIV, tuberculosis, and malaria during 1990-2013: A systematic analysis for the Global Burden of Disease Study 2013. Lancet 2014; 384:1005-70.2.

2. WHO. Global Update on HIV Treatment. World Health Organization 2018.

3. UNAIDS. The Gap Report. Joint United Nations Programme on HIV/AIDS 2014.

4. UNAIDS. Fact Sheet on HIV-2017. Global statistics. 2018.

5. Daniel MD et al. Protective effects of a live attenuated SIV vaccine with a deletion in the nef gene. Science 258: 1938-1941, 1992

6. Baba TW et al. Pathogenicity of live, attenuated SIV after mucosal infection of neonatal macaques. Science 267: 1820-1825, 1995

7. Pinto LA et al. HIV-specific immunity following immunization with HIV synthetic envelope peptides in asymptomatic HIV-infected patients. AIDS 13: 335-339, 2002

8. Kran AMB et al. HLA- and dose-dependent immunogenicity of a peptide-based HIV-1 immunotherapy candidate (Vacc 4x). AIDS 18: 1875-1883, 2004

9. Barouch DH et al. Eventual AIDS vaccine failure in a rhesus monkey by viral escape from cytotoxic $\mathrm{T}$ lymphocytes. Nature 415: 335-339, 2002

10. Boyer JD et al. Vaccination of seronegative volunteers with a human immunodeficiency virus type 1 env/rev DNA vaccine induces antigen-specific proliferation and lymphocyte production of beta-chemokines. J Infect Dis 181: 476-483, 2000

11. Schnell MJ et al. Recombinant rabies virus as potential live-viral vaccines for HIV-1. ProcNatlAcadSci U S A 97: 3544-3549, 2000

12. Hansen SG et al. Profound early control of highly pathogenic SIV by an effector memory T-cell vaccine.Nature, early online publication, doi:10.1038/nature10003, May 2011

13. Zhang $\mathrm{H}$ et al. Human immunodeficiency virus type $1 \mathrm{Gag}$-specific mucosal immunity after oral immunization with papillomavirus pseudoviruses encoding Gag. J Virol 78: 10249-10257, 2004

14. Ensoli B et al. Candidate HIV-1 tat vaccine development: from basic science to clinical trials. AIDS 20(18):2245-2261, 2006

15. Ensoli B et al. Therapeutic immunization with HIV-1 tat reduces immune activation and loss of regulatory TCells and improves immune function in subjects on HAART. PLoS ONE 5(11): e13540. doi:10.1371/journal.pone.0013540, 2010

16. Flynn NM, Forthal DN, Harro CD, Judson FN, Mayer KH, Para MF. Placebo-controlled phase 3 trial of a recombinant glycoprotein 120 vaccine to prevent HIV-1 infection. J Infect Dis. 2005; 191:654-665. [PubMed: 15688278]

17. Pitisuttithum P, Gilbert P, Gurwith M, Heyward W, Martin M, van Griensven F, Hu D, Tappero JW, Choopanya K. Randomized, double-blind, placebo-controlled efficacy trial of a bivalent recombinant glycoprotein 120 HIV-1 vaccine among injection drug users in Bangkok, Thailand. J Infect Dis. 2006; 194:1661-1671. [PubMed: 17109337]

18. Mascola JR, Snyder SW, Weislow OS, Belay SM, Belshe RB, Schwartz DH, Clements ML, Dolin R, Graham BS, Gorse GJ, et al. Immunization with envelope subunit vaccine products elicits neutralizing antibodies against laboratory-adapted but not primary isolates of human immunodeficiency virus type 1. The National Institute of Allergy and Infectious Diseases AIDS Vaccine Evaluation Group. J Infect Dis. 1996; 173:340-348. [PubMed: 8568294] 
19. Haynes BF, Verkoczy L, Kelsoe G. Redemption of autoreactive B cells. ProcNatlAcadSci U S A. 2014; 111:9022-9023. [PubMed: 24920593]

20. Gilbert PB, Peterson ML, Follmann D, Hudgens MG, Francis DP, Gurwith M, Heyward WL, Jobes DV, Popovic V, Self SG, et al. Correlation between immunologic responses to a recombinant glycoprotein 120 vaccine and incidence of HIV-1 infection in a phase $3 \mathrm{HIV}-1$ preventive vaccine trial. J Infect Dis. 2005; 191:666-677. [PubMed: 15688279]

21. Tongo M, Burgers WA. Challenges in the design of a T cell vaccine in the context of HIV-1 diversity. Viruses. 2014; 6:3968-3990. [PubMed: 25341662]

22. Ministry of Public Health-Thai AIDS Vaccine Evaluation Group. 2011. Screening and evaluation of potential volunteers for a phase III trial in Thailand of a candidate preventive HIV vaccine (RV148). Vaccine 29:428592

23. Rerks-Ngarm S, Pitisuttithum P, Nitayaphan S, et al. 2009. Vaccination with ALVAC and AIDSVAX to prevent HIV-1 infection in Thailand. N. Engl. J. Med. 361:2209-20

24. Kayeyi N, Fylkesnes K, Michelo C, Makasa M, Sandøy I. Decline in HIV prevalence among young women in Zambia: National-level estimates of trends mask geographical and socio-demographic differences. PLoS One 2012; 7:e33652.

25. Sekar R, Amudhan M, Sivashankar M, Veeran R, Jayachandran C, Mythreyee M. Declining trend of HIV infection among the rural population of South India - A comparison of HIV prevalence in high risk and low risk groups. J Infect 2011; 63:91-2.

26. Sekar R, Amudhan M, Sivashankar M, Mythreyee M. Recent trends in HIV prevalence in a remote setting of southern India: Insights into arranging HIV control policies. J Infect DevCtries 2013; 7:838-43.

27. Excler JL. AIDS vaccine development: perspectives, challenges and hopes. Indian J Med Res 2005 Apr; 121 : 568-81.

28. Ohja VP, Pradhan BK. The macroeconomic and sectoral impacts of HIV and AIDS in India: a CGE study. New Delhi; National Council of Applied Economic Research, National AIDS Control Organization, United Nations Development Programme: 2006.

29. Sahni AK, Prasad VV, Seth P. Genomic diversity of human immunodeficiency virus type-1 in India. Int J STD AIDS 2002; 13: 115-8esani A. Coutinho L. AIDS vaccine trials in India: ethical benchmarks and unanswered questions. Indian J Med Ethics 2007; 4: 2-3.

30. Garrison C. Intellectual property rights and vaccines in developing countries. Background paper for WHO workshop 2004 Apr 19-20; Geneva.

31. Gadkari D A, Moore D, Sheppard H W, Kulkarni SS, Mehendale SM, Bollinger RC. Transmission of genetically diverse strains of HIV-1 in Pune, India. Indian J Med Res 1998 Jan; 107: 1-9.

32. Maartens G, Celum C, Lewin SR. HIV infection: Epidemiology, pathogenesis, treatment, and prevention. Lancet 2014; 384:258-71.

33. Deeks SG, Lewin SR, Havlir DV. The end of AIDS: HIV infection as a chronic disease. Lancet 2013;382:152533.

34. Tanser F, Barnighausen T, Grapsa E, Zaidi J, Newell ML. High coverage of ART associated with decline in risk of HIV acquisition in rural KwaZulu-Natal, South Africa. Science 2013; 339:966-71.

35. Rerks-Ngarm S, Paris RM, Chunsutthiwat S, et al. 2013. Extended evaluation of the virologic, immunologic, and clinical course of volunteers who acquired HIV-1 infection in a phase III vaccine trial of ALVAC-HIV and AIDSVAX B/E. J. Infect. Dis. 207:1195-205. 